\title{
Efficient Rooting System for Apple “M.9” Rootstock Using Rice Seed Coat and Smocked Rice Seed Coat
}

\author{
Matiullah Akbari, ${ }^{1}$ Tsutomu Maejima, ${ }^{2}$ Shungo Otagaki, ${ }^{1}$ \\ Katsuhiro Shiratake, ${ }^{1}$ and Shogo Matsumoto ${ }^{1}$ \\ ${ }^{1}$ Graduate School of Bioagricultural Sciences, Nagoya University, Chikusa, Nagoya 464-8601, Japan \\ ${ }^{2}$ Nagano Fruit Tree Experiment Station, Nagano 382-0072, Japan
}

Correspondence should be addressed to Shogo Matsumoto; shogo@agr.nagoya-u.ac.jp

Received 7 October 2015; Accepted 15 December 2015

Academic Editor: Silvia Imhoff

Copyright (C) 2015 Matiullah Akbari et al. This is an open access article distributed under the Creative Commons Attribution License, which permits unrestricted use, distribution, and reproduction in any medium, provided the original work is properly cited.

"M.9" rootstock is considered as one of the most useful apple (Malus x domestica Borkh.) rootstocks; it produces dwarfing trees efficiently. As "M.9" rootstock shows a poor, brittle, and shallow roots system, we grafted "M.9" rootstocks onto "Marubakaidou" (M. prunifolia Borkh. var. ringo Asami Mo 84-A). We then propagated them by mound layering to establish a high-density root system. It was found that covering the roots with rice seed coat (RSC), RSC + smoked rice seed coat (SRSC), and vermiculite during mound layering was effective for the initiation of rooting. Utilizing RSC and SRSC seemed especially effective for producing "M.9" roots efficiently.

\section{Introduction}

Apple (Malus $\mathrm{x}$ domestica Borkh.) is the second most significant cultivated fruit tree (80.82 million metric tons were produced in 2013) worldwide after banana [1]. Rootstocks of apple trees are usually used to propagate apple cultivars, and clonal rootstock is propagated by asexual or vegetative propagation, such as cutting and tissue culture [2]. There are two series of clonal apple rootstocks: East Malling (EM) and Malling Merton (MM), both of which are virus-free and possess size-controlling characteristics [3]. The clonal apple rootstocks consist of three distinct types based on the tree sizes of scions (cultivars): dwarf-type "M.27," "M.9," and "M.26"; semidwarf-type "MM.106," "MM.104," "M.7," "M.4," and "M.2"; and no dwarf-type "MM.111," "MM.109," and "M.10" [3].

In this study, we focused on "M.9" rootstocks because apple growers desire dwarf apple trees with high quality fruits that can be reaped easily and safely, especially at harvest time $[4,5]$. However, the "M.9" rootstock has a problem with poor, shallow, and fragile root production. Although the rooting of "M.9/29" was improved greatly by its transformation with the rolB gene from Agrobacterium rhizogenes [6], the transgenic apple seems to difficultly obtain government permission or public understanding, especially in Japan. On the other hand, layering is the method used for root propagation in which a portion of stem or limb grows roots while still attached to the mother plant, and it is the useful propagation method for the clonal rootstock of "M.9" [3]. For obtaining the "M.9" roots more efficiently, we investigated the effectiveness of rice seed coat (RSC), smoked rice seed coat (SRSC), and vermiculite for the "M.9" root production.

\section{Materials and Methods}

2.1. Plant and Covering Material. The experiment was conducted in 2013 and 2014. The rootstocks "M.9" Nagano (ACLSV-free) and "Marubakaidou" (M. prunifolia Borkh. var. ringo Asami Mo 84-A) from Nagano Fruit Experimental Station were used as scions and stocks, respectively. Both scions and stocks were selected from one-year-old branches.

Rice seed coat (RSC) and smoked rice seed coat (SRSC) were obtained from the Experimental Farm of TOGO field in Nagoya University and Kinahta Mizunami Shop in Mizunami 


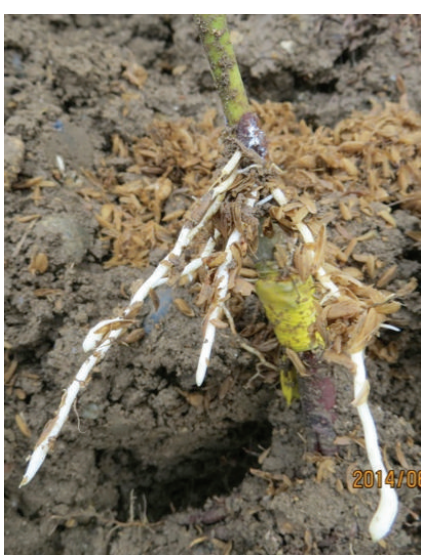

RSC

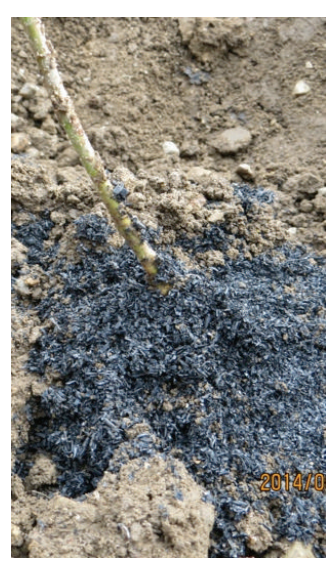

SRSC

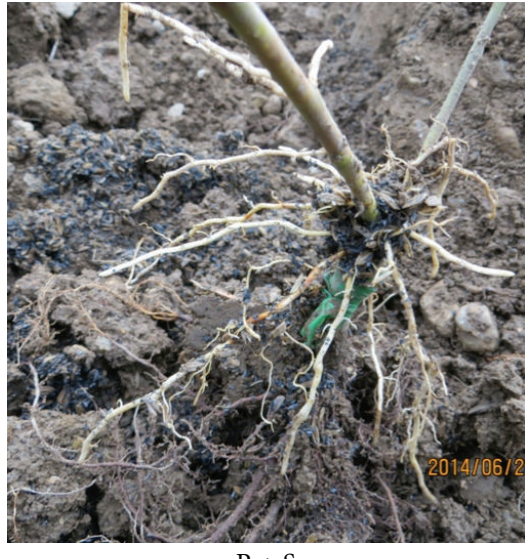

$\mathrm{R}+\mathrm{S}$

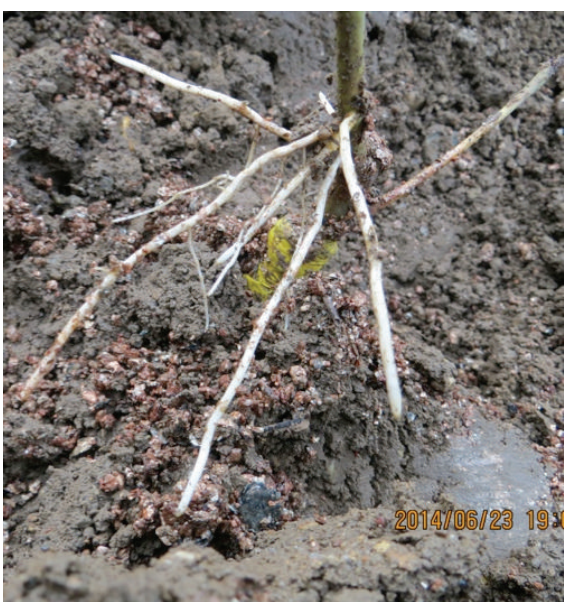

Verm.

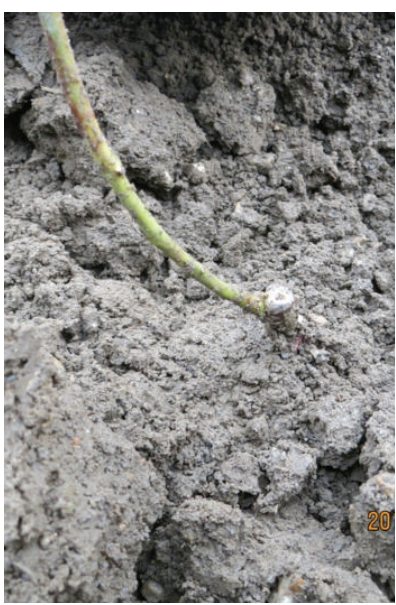

Soil

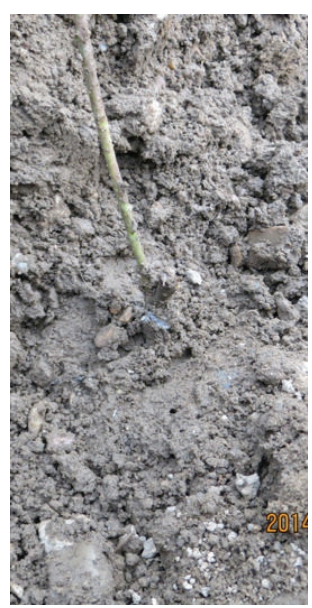

Cont.

Figure 1: "M.9" roots produced after one-month treatment of rice seed coat (RSC), smoked rice seed coat (SRSC), combined 50\% RSC and $50 \%$ SRSC $(\mathrm{R}+\mathrm{S})$, vermiculite (Verm.), soil (Soil), and no soil (Cont.).

City, Gifu, Japan. The vermiculite was obtained from Asian Seed Co., Ltd., Japan.

2.2. Grafting and Layering of "M.9" Rootstock. Bark grafting for "M.9" Nagano scions and "Marubakaidou" stocks was conducted in March at Nagano Experimental Station. They were planted in ten columns and seven rows with $50 \mathrm{~cm}$ and $100 \mathrm{~cm}$ spaces between plants and rows, respectively, at the experimental field in Nagoya University.

For mound layering, the grafted "M.9" Nagano rootstocks (5 and 65 in 2013 and 2014, resp.) were covered with RSC (two and 15 in 2013 and 2014, resp.), SRSC (two and 10 in 2013 and 2014, resp.), $50 \% \times 50 \%$ mix of RSC and SRSC $(\mathrm{R}+\mathrm{S})(10$ in 2014), vermiculite (10 in 2014), and soil and with no cover (control) (one and 10 in 2013 and 2014, resp.), when their height exceeded $3 \mathrm{~cm}$. A week after the covering, all of the rootstocks including control were covered by soil, especially when their height exceeded $10 \mathrm{~cm}$, and covering with soil extended until they were $30 \mathrm{~cm}$ tall.

2.3. Digging and Measurement of "M.9" Rootstock. Digging out one or two of each of the grafted "M.9" rootstocks was carried out on the 22nd of June, August, and October 2014 and backfilled. Finally, all the grafted "M.9" rootstocks were dug out on the first of December, 2014. After digging them out we measured the number, length, diameter, and the fresh and dry weight of the roots, which appeared from the covering material layer.

\section{Results and Discussion}

3.1. Root Initiation of "M.9" Nagano. We collected "M.9" Nagano and "Marubakaidou" rootstocks at Nagano and then grafted "M.9" Nagano as scions on the next day at Nagoya University in 2013, but all the grafted "M.9" rootstocks died after being covered with RSC, SRSC, or soil (results not shown). The rootstocks seemed to have lost their freshness and the amount of their callus, which plays a critical role in graft union before grafting. As the timing of grafting seemed to be important, we collected both rootstocks and grafted them on the same day in Nagano in 2014. All grafted "M.9" rootstocks grew well except for three rootstocks covered by SRSC. SRSC seemed to have strong water-leaching ability; therefore, those rootstocks might have died from being dried 


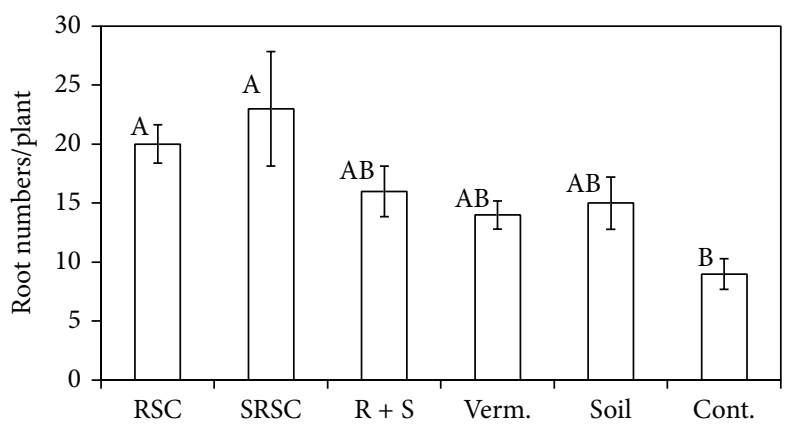

(a)

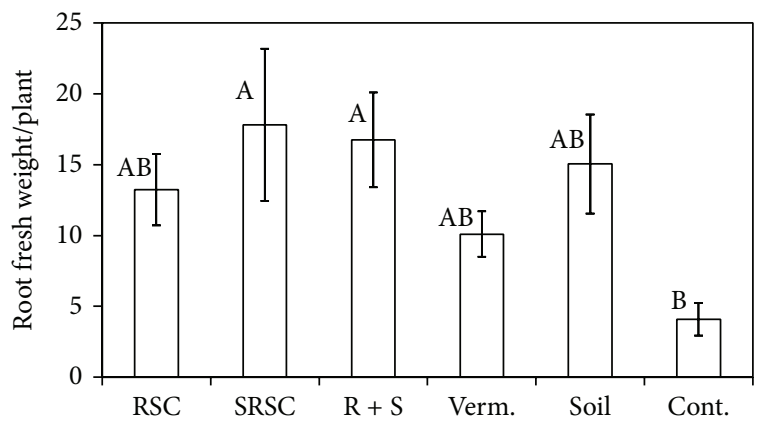

(b)

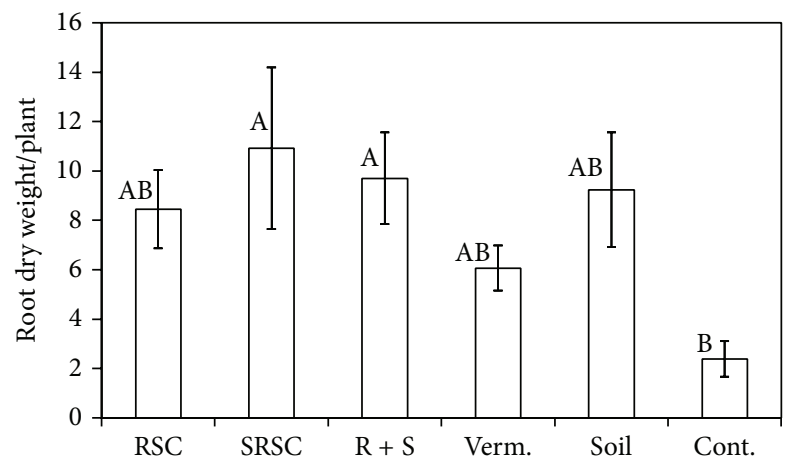

(c)

Figure 2: Number (a), dry (b) and fresh weight (c) of "M.9" roots per plant which appeared after 6-month treatment with rice seed coat (RSC), smoked rice seed coat (SRSC), combined 50\% RSC and 50\% SRSC (R + S), vermiculite (Verm.), soil (Soil), and no soil (Cont.). Values represent the means \pm SE of 4 or 7 plants, and those with different letters differed significantly at $P<0.01$ by one-way anova followed by Dunnett's multiple comparison test.

out. To solve the problem, we changed the watering schedule from once to twice per 24 hours.

Newly generated roots were obtained on the 22nd of June at rootstock sites covered with $\mathrm{RSC}, \mathrm{R}+\mathrm{S}$ (RSC + SRSC), and vermiculite; however, no roots were induced with SRSC, soil, or control (Figure 1). The greatest number of roots was produced by $\mathrm{R}+\mathrm{S}$. Generally, development and growth of roots were strongly affected by soil texture, moisture, fertility, and aeration [7]. As soil and control (covered by soil one week after) conditions are heavy compared to RSC, RSC + SRSC, and vermiculite conditions, the "M.9" rootstocks covered by soil seemed to damage healthy buds before root initiation. RSC, RSC + SRSC, and vermiculite affected the bud stem colors of "M.9" rootstocks and changed them to yellow or yellowish, which might induce root initiation early. In case of SRSC, the water supply seemed to cause a depression of the SRSC layer when covered by soil. Therefore, roots were not observed in June; however, the roots of the same degree as RSC, RSC + SRSC, and vermiculite were produced on the 22nd of August and October (results not shown). Although the initiation of rooting was delayed at RSC covering, rooting efficiency including root numbers and weight seemed to be recovered from its fertilizer effect. Similar timing of "M.9" root growth initiation has been reported by Psarras et al. [8].

3.2. Root Generation of "M.9" Nagano. Generalized root numbers were significantly higher in RSC (20.1 $\pm 1.6 /$ plant $)$ and SRSC $(22.5 \pm 4.9 /$ plant $)$ than in control ( $8.6 \pm 1.3 /$ plant $)$ on the first of December (Figure 2(a)). The number of roots was also higher in $\mathrm{R}+\mathrm{S}$, vermiculite, and soil than in control but not significantly (Figure 2(a)). Tamai et al. [9] reported that "M.9" Nagano rootstock that produced roots by mound layering lost the colors of young shoots (etiolating) and that the average root numbers per shoot were about 10 when harvested from 3- to 5-year-old stool bed. The average root numbers increased twice by utilizing RSC and SRSC (Figure 2(a)). The combination of etiolation and banding shading increased rooting significantly; in fact, "M.7" and "MM.106" clonal rootstocks produced significantly higher roots under dark treatments than those that were treated by persistent light [10-12]. Higher root numbers from RSC and SRSC covering than from those of other materials might have been caused by the effective etiolation of buds by shading (Figure 2(a)).

Regarding fresh and dry weight of roots, SRSC and R + $S$ brought about heavier weight than those of the control (Figures 2(b) and 2(c)). Concerning root length and diameter, however, we could not detect any significant differences among the treatment materials (results not shown). Before use, SRSC was changed from nonorganic (RSC) to organic material (ash), which had dark colors and contained more fertilizer. Therefore, SRSC and $\mathrm{R}+\mathrm{S}$ containing ash and a half of SRSC ash, respectively, brought about heavier root fresh and dry weights than the control (Figures 2(b) and 2(c)). 
Vermiculite contains no fertilizer, and it seemed to therefore produce poor roots among the treated materials (Figures 2(b) and 2(c)).

\section{Conclusions}

We have compared the effectiveness of RSC, SRSC, vermiculite, and soil against root proliferation of "M.9" apple rootstock. Although SRSC did not cause early root initiation, the final root numbers and fresh and dry weight of roots treated with it were the greatest among the materials. It was suggested that SRSC was the most suitable material for "M.9" apple root propagation by mound layering, but as SRSC needs watering twice a day $\mathrm{R}+\mathrm{S}$ could be used alternately. As the weights of RSC and SRSC are far lighter than that of soil, these materials should be used instead of soil for the reduction of labor.

\section{Conflict of Interests}

The authors declare that there is no conflict of interests regarding the publication of this paper.

\section{Acknowledgments}

The authors are indebted to Dr. T. Tsuge for supplying the rice seed coat. They also wish to thank Dr. R. Nakajima for his technical assistance. This research was carried out under the Project for the Promotion and Enhancement of the Afghan Capacity for Effective Development (PEACE).

\section{References}

[1] Statista, 2013, http://www.statista.com/statistics/264001/worldwide-production-of-fruit-by-variety/.

[2] S. J. Wertheim and A. D. Webster, "Propagation and nursery tree quality," in Apples: Botany, Production and Uses, D. C. Ferree and I. J. Warrington, Eds., pp. 125-151, CABI Publishing, Oxford, UK, 2003.

[3] A. D. Webster and S. J. Wertheim, "Apple rootstocks," in Apples: Botany, Production and Uses, D. C. Ferree and I. J. Warrington, Eds., pp. 91-124, CABI Publishing, Oxon, UK, 2003.

[4] C. Di Vaio, C. Cirillo, M. Buccheri, and F. Limongelli, "Effect of interstock (M.9 and M.27) on vegetative growth and yield of apple trees (cv 'Annurca')," Scientia Horticulturae, vol. 119, no. 3 , pp. 270-274, 2009.

[5] V. Gjamovski and M. Kiprijanovski, "Influence of nine dwarfing apple rootstocks on vigour and productivity of apple cultivar 'Granny Smith,' Scientia Horticulturae, vol. 129, no. 4, pp. 742746, 2011.

[6] L.-H. Zhu, A. Holefors, A. Ahlman, Z.-T. Xue, and M. Welander, "Transformation of the apple rootstock M.9/29 with the rolB gene and its influence on rooting and growth," Plant Science, vol. 160, no. 3, pp. 433-439, 2001.

[7] W. W. Yocum, "Root development of young Delicious Apple trees as affected by soils and cultural treatment," Historical Materials from University of Nebraska-Lincoln Extension, 1937, http://digitalcommons.unl.edu/extensionhist/910.

[8] G. Psarras, I. A. Merwin, A. N. Lakso, and J. A. Ray, "Root growth phenology, root longevity, and rhizosphere respiration of field grown 'Mutsu' apple trees on 'Malling 9' rootstock,' Journal of the American Society for Horticultural Science, vol. 125, no. 5, pp. 596-602, 2000.

[9] H. Tamai, T. Ono, H. Koike, I. Shigehara, and A. Iijima, "Morphological characteristics of 4 clones of M.9 apple rootstock and propagation of M.9 Nagano in the stool bed," Journal of the Japanese Society for Horticultural Science, vol. 1, no. 4, pp. 241244, 2002.

[10] B. Maynard and N. Bassuk, "Etiolation as a tool for rooting cuttings of difficult-to-root woody plants," in Proceedings of the International Plant Propagators' Society (IPPS '85), vol. 34, pp. 488-494, 1985.

[11] N. Bassuk, D. Miske, and B. Maynard, "Stock plant etiolation for improved rooting of cuttings," Proceedings of the International Plant Propagators' Society, vol. 34, pp. 543-550, 1985.

[12] T. Sharma, M. Modgil, and M. Thakur, "Factors affecting induction and development of in vitro rooting in apple rootstocks," Indian Journal of Experimental Biology, vol. 45, no. 9, pp. 824829, 2007. 


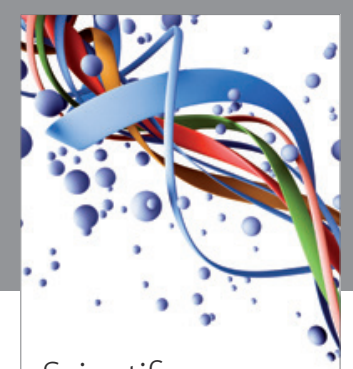

Scientifica
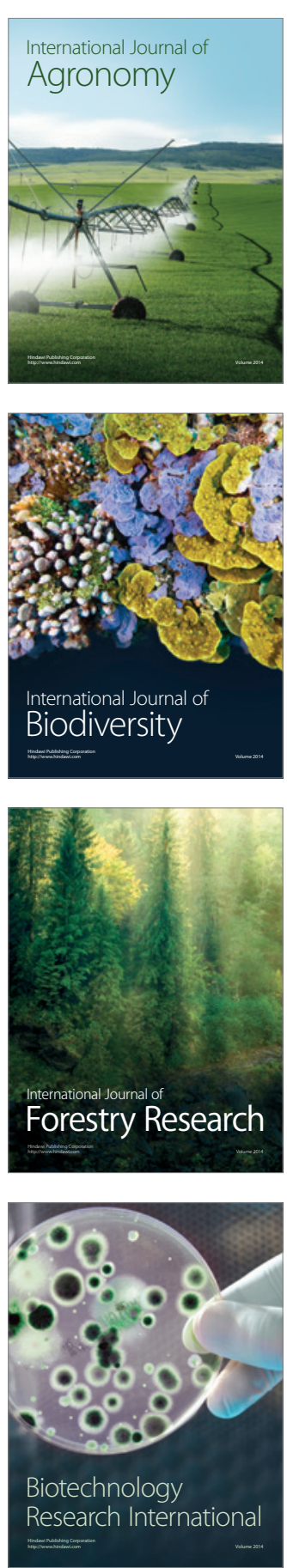
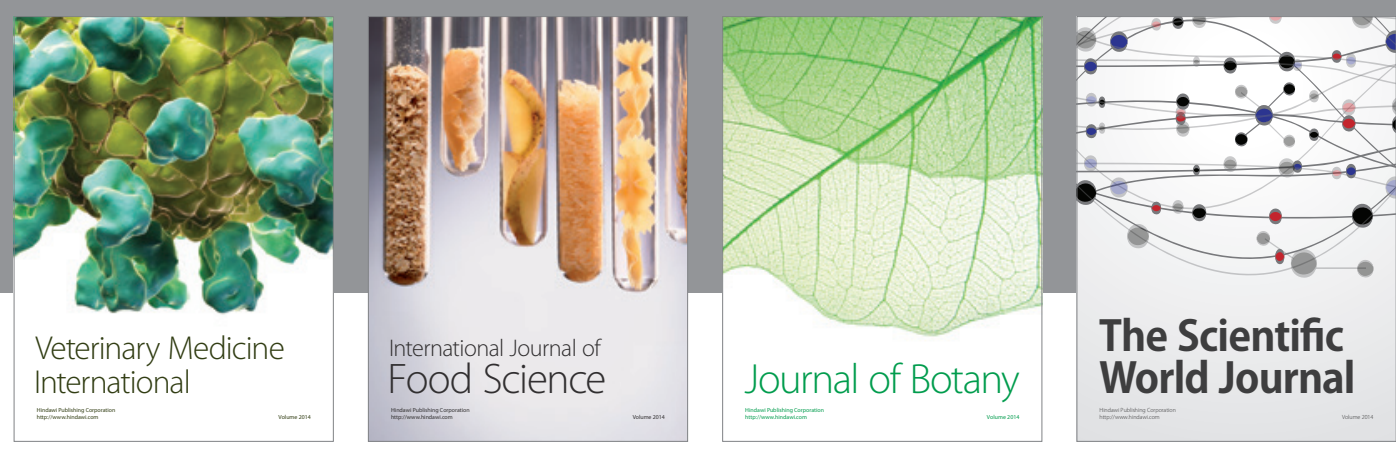

The Scientific World Journal
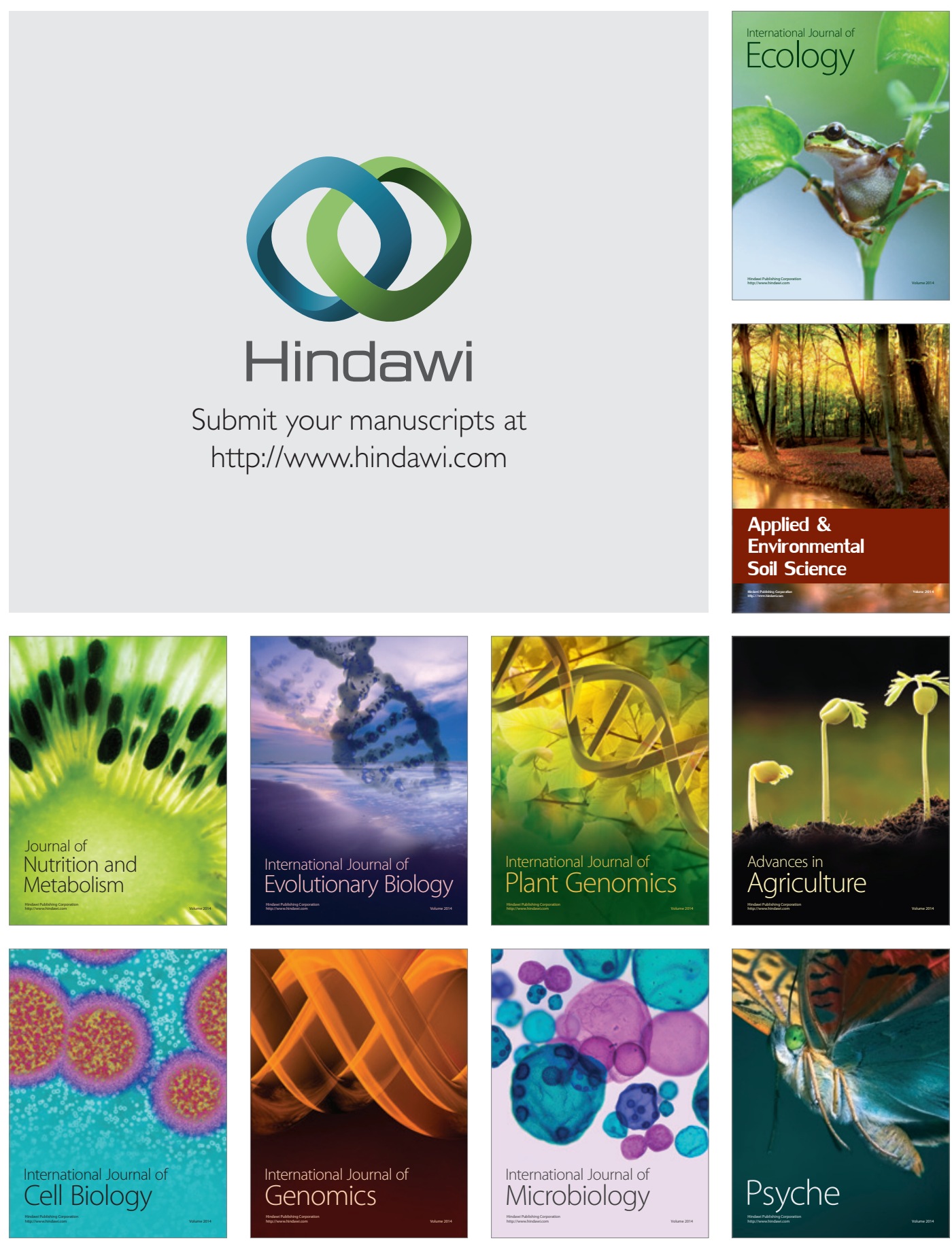